\title{
HEALTH LEADERSHIP LESSONS FROM A FINE DETECTIVE
}

\author{
Dinesh Arya \\ ACT Health, Canberra, Australia
}

Correspondence: Dinesh.Arya@act.gov.au

\begin{abstract}
OBJECTIVE:

To explore lessons on leadership from interactions and success of two very fine detectives - Sherlock Holmes and Dr Watson
\end{abstract}

\section{METHODS:}

From the review of Sir Arthur Conan Doyle's depiction of Sherlock Holmes, some clear and useful lessons have been drawn for health leaders. An erratic, unsystematic Sherlock Holmes and an analytical, systematic and introspective Dr Watson provide useful lessons for health leaders on trust, teamwork and how complementary abilities enable achievement of a great outcome.

\section{CONCLUSIONS:}

It is really important for health leaders to not forget the elementary message to remain focused on care provision, enable the provision of care that the community wishes to receive and avoid of the temptation of making decisions without appropriate information set to inform those decisions.

\section{KEYWORDS}

leadership, health, management
Sherlock Holmes, Dr. Watson and their interactions have fascinated many. Their success in solving some puzzling scenarios has also generated an interest in the differences in the way they go about their business. An erratic, unsystematic Sherlock Holmes has an eye for detail and is able to connect seemingly unconnected pieces of evidence and do so in a perceptive, logical and rigorous manner. (1) He has exceptional deductive abilities. (2) Dr. Watson, on the other hand, is analytical, systematic and introspective. He has the ability to dig into details, however, has the unique ability to also put aside his own analysis and go with Sherlock Homes' hunch, who he seems to trust more than he trusts his own scientific, analytical and systematic approach to identify a problem. More importantly, the pair are able to circumvent the bureaucracy in an effort to uncover the truth. This requires testing boundaries, norms and sometimes bypassing procedures, yet doing so in an honest and ethical manner.

All very worthy observations for leaders in relation to trust, teamwork and how complementary abilities enable achievement of a great outcome.

Tales of Sherlock Holmes and Watson have also generated commentary on lessons that can be learned on leadership.

(3) Chaturvedi captures some important lessons including the following:

- The need for Sherlock Holmes to know what other people don't know ('My name is Sherlock Holmes. It is my business to know what other people don't know.' Sherlock Holmes in The Adventure of the Blue Carbuncle).

A very clear lesson for the health sector is that providing leadership in as complex a sector as healthcare requires expertise in a wide range of 
arenas - from clinical systems and process improvement, to technology and innovation, to financial management. (4) It is important that health leaders know everything about their business, including those details that others don't know.

- Not to theorise before one has data or information ('It is a capital mistake to your eyes before one has data. Insensibly one begins to twist facts to suit theories, instead of theories to suit facts.' Sherlock Holmes in A Scandal in Bohemia).

It is important for decision-makers and leaders to be objective and base decisions on facts. To manage complexity and change, there is a need for health leaders with technical expertise to understand evidence, technology, innovation, value, complexity and change (4).

- Weakness in one part can lead to compensatory excellence in another (Weakness in one limb is often compensated for by exceptional strength in the others.' Sherlock Holmes in The Adventure of the Six Napoleons and Other Cases).

It is true that a weakness in one part of the organisation can unleash over-compensatory strength in another part. Weakness should not always be considered a liability.

- Problem-solving requires exclusion of impossible but not improbable ('When you have eliminated the impossible, whatever remains however improbable must be the truth.' Sherlock Holmes in The Sign of the Four).

At times it is not easy to get to the bottom of things. However, the strategy of not excluding 'improbables' does help to get to the root causes of a problem. Not spending enough time and energy asking 'why' a few times, interrogating evidence and systematically analysing systems and processes even though the error or omission may have occurred in the past, is often the reason for new problems and challenges remaining hidden.

Hashim has commented on Sherlock Holmes' ability to give importance to what he cannot see as much as what he can. These include paying attention to detail, having a trustworthy companion like Dr. Watson (even if they do not always see eye to eye on a lot of matters), acceptance of perspectives other than one's own, need for a depth of knowledge and a hunger to attain new knowledge, taking the time to think things through, ponder on the findings to make sense of it all and being passionate about what one does irrespective of rewards. (2)

Webb made very astute observations about an observant Sherlock Holmes. (5) 'You see, but you do not observe. The distinction is clear.' Webb makes an important point here that leaders must recognise patterns and understand the significance of what they see. Sherlock Holmes had the ability to gather the facts and then separate those which were crucial, from others which were merely incidental (Sherlock Holmes in The Crooked Man). Sherlock Holmes' dialogue 'That was a curious incident' signifies Sherlock Holmes curiosity in observations that did not elicit interest or response in occurrences by others.

Herron also captures some aspects from Sir Arthur Conan Doyle's depiction of Sherlock Holmes as a remarkable detective. (6) He observes that details matter; partners are indispensable; there is more than one way to approach the problem; but also the fact that even when problems are solved many questions remain unanswered.

These are important lessons for health leaders. Reforms must always be informed by a detailed analysis of both benefits of potential consequences. The complexity of providing leadership in healthcare lies in having skills and expertise to ensure safe service delivery; ensuring treatment effectiveness considerations guide optimisation of service delivery; evidence base and best practice considerations determine what should be provided, by whom and how change should be implemented; technology and innovation is continuously assessed for use; delivery systems and processes are continuously improved; understanding of supply and demand considerations to ensure that best value is delivered for the consumer, community and society in general and models of care; and therefore the workforce is continuously configured and aligned to deliver the most effective and appropriate interventions possible. (4)

Many commentators argue about the need for the reform idea to be shared and even encourage organisations to develop a vision by consensus. Indeed, a new vision has to be shared vision that everyone can relate to. However, if 
transformation is not about maintaining status quo, but a change in paradigm that leads to exponential gain, the vision sometimes may need to be new and different that may not be accepted by the dominant majority and may require development of a new coalition (7),

McLaughlin and Cox note that even though Sherlock Holmes uses deductive logic he almost certainly at certain points also uses 'retroductive' process i.e. the process involving taking a visible and tangible endpoint and then reasoning backward by examining where earlier in the leader's experience there were indications of the eventual outcome. (6)

\section{What might be some other very interesting learnings for leaders in healthcare?}

\section{"It's elementary, my dear Watson!"}

Working in a health bureaucracy, some decision makers often forget that they are in the business of providing care. The bureaucratic systems and processes are essential to ensure consistent and systematic management, however, when financial considerations start taking precedence over care considerations in the name of efficiency and effectiveness to provide more and better care, the 'elementary' message that healthcare provision must be all about providing healthcare, is sometimes lost. The 'CARE' in terms of healthcare provision must always be Cclinical needs focused, A- appropriate, R-respectful, Eevidence-based. From a recipient or patient's perspective, the care has to be all about being $C$ - courteous, Aaccessible, R-responsive and E-explicit.

It is quite possible that Sir Arthur Conan Doyle may have specifically chosen a character to balance the eccentric and insecure Sherlock Holmes, in the form of a doctor and called him Watson. Incidentally, the letters in the name Watson do signify the need for W-waste elimination, Aappropriate, T-transparent, S-safe, O-outcome focused and $\mathrm{N}$-innovative healthcare.

\section{"Watson, you idiot. Somebody stole our tent ..."}

Sherlock Holmes and Watson went camping. Watson is suddenly shaken up by Sherlock and asked "look up, Watson. What do you see?". "I see the stars." "And what does that tell you?" "Astronomically, it tells me that Jupiter is in the fourth house. Meteorologically, it tells me that it will be bright tomorrow. Philosophically, it tells me that God is all-powerful and we are mere dust compared to him. Why, Sherlock what do you see?"

"Watson, you idiot! Someone's stolen our tent!"

This may well be the funniest joke in fictional literature, however, signifies the irony in healthcare provision. In an effort to provide efficient, effective, right and appropriate care, it is important to ensure that the care that the health system and health professionals consider right and appropriate is the care that the recipient (or the patient), their families and the wider community wish to have. When providing complex and life-prolonging interventions, it is important to remember something that can be done, may not necessarily be something that the recipient of care wants to be done. A scientific Dr. Watson, with knowledge of astronomy, meteorology and philosophy could see everything but not that the tent was missing.

\section{"The temptation to form premature theories upon insufficient data is the bane of our profession"}

It is not unusual for healthcare leaders to theorise what might be in the best interest of the recipients of care, their families and the wider community. Many strategic plans are developed, operationalised and precious resources invested with little data or information. Sometimes it is as if people delivering health care and those receiving it are in two different 'camps.' People responsible for the delivery of healthcare convince themselves, often based on partial or inadequate information, that recipients of care are going to benefit from it without necessarily understanding the expectations, perspectives and desires of those receiving health care. Decisions are made based on misperceptions which lead to mistrust, wastage of resources and perpetual restructuring of healthcare systems and processes.

All of the above is definitely not as a result of lack of leadership or can be attributed to bad culture. In healthcare, we have well-meaning decision makers who make the best effort to provide the most appropriate strategy and invest valuable resources. However, this must be done with the benefit of information. It is true that often data or information is just not available and delaying decision-making because of inadequate information would also be counter-productive. In such situation transparency, openness and explicitness about the information that is available and that forms the basis for decision-making is important. 
The belief that a strategic plan just has to be written because one is expected and then has to be operationalised so that performance could be measured, misses the point completely.

\section{"That was a curious incident!"}

It is with enthusiasm and confidence that we endeavour to provide high quality, safe, consistent, reliable, effective, efficient and appropriate health care. However, it is important that the healthcare delivery system is developed with careful consideration of the entire environment in which care is delivered. This requires effective engagement with all stakeholders, working to a common goal so that all perspectives are considered in formulating the strategy and the plan for healthcare delivery. A care delivery system must consider the needs of recipients, providers and of the wider community. Innovation and solution generation must focus on the needs and expectations of the recipients of care as well as make the best use of the talent that is available to meet those needs and expectations.

It is curious that the most visible displays in many healthcare organisations are their strategic plans, performance frameworks, performance indicators and display of achievements. It is not incomprehensible to develop a health care system in which back room functions that support healthcare delivery are invisible (including strategic plans, value statements, quality improvement frameworks, monitoring and evaluation reports, audit systems and the like). Instead, the effort should go in providing care. If the focus of a healthcare organisation begins to shift from those it is there to serve to those who serve, the entire system is at risk of becoming a servant to meet the needs of providers rather than the recipients.

\section{"In solving a problem of this sort, the grand thing is to be able to reason backward"}

It is sometimes very useful to consider what is it that we are trying to achieve and then work backward to develop systems and processes that will enable us to achieve it. Of course, it is always easy to conceptualise something with an expectation that it will deliver the output or outcome desired or necessary. Unfortunately, such conceptualisation is not always successful.
1. Thompson A. On leadership, Sherlock Holmes and the analytical leader. Accessed February 12, 2019. https://linked2leadership.wordpress.com/2013/06/18/ on-leadership-sherlock-holmes-and-the-analyticalleader/.

2. Hashim I. Thinking Like Sherlock Holmes. Accessed February 12, 2019.

https://leaderonomics.com/leadership/thinking-likesherlock-holmes.

3. Chaturvedi M. 7 Leadership lessons you can learn from Sherlock Holmes. Accessed February 12, 2019. https://www.linkedin.com/pulse/7-leadership-lessonsyou-can-learn-from-sherlock-chaturvedi-dms-hr/.

4. Arya DK. Do our leaders have technical expertise to lead change. Asia Pacific Journal of Health Management 2015; 10(3):S144-S146.

5. Webb K. How Leaders Can Be As Observant As Sherlock Holmes. Accessed February 12, 2019. https://keithwebb.com/how-leaders-can-be-asobservant-as-sherlock-holmes/.

6. Herron M. Leadership thoughts from Sherlock Holmes. Accessed February 12, 2019.

https://www.clintonpublicschools.com/site/default.as px?PageType $=3 \&$ ModulelnstancelD $=6292 \& \mathrm{ViewID}=\mathrm{DE}$ DCCD34-7C24-4AF2-812A-

33C0075398BC \&RenderLoc $=0 \&$ FlexDatalD $=13148 \& \mathrm{Pag}$ $\mathrm{elD}=4840 \& \mathrm{Tag}=$.

7. Arya DK. So, you want to lead a transformational change? Asia Pacific Journal of Health Management $2012 ; 7(2): 8-14$

8. McLaughlin M, Cox E. Leadership Coaching: Developing braver leaders. New York: Routledge, 2016.

\section{References}

